\title{
SORPTION BEHAVIOR OF ORGANIC MOLECULES ON POROUS PAPER MATERIAL
}

\author{
LISA HOFFELLNER ${ }^{* * * *}$ and ERICH LEITNER ${ }^{*, * *}$ \\ *Institute of Analytical Chemistry and Food Chemistry, Graz University of Technology, \\ 8010 Graz, Austria \\ ${ }^{* *}$ CD-Laboratory for Mass Transport through Paper, Graz University of Technology, \\ 8010 Graz, Austria \\ Corresponding author: L. Hoffellner, lisa.hoffellner@tugraz.at
}

Received January 27, 2020

\begin{abstract}
The application of paper in a large range of fields is highly desired because it has a variety of favorable characteristics. Especially in the sector of food packaging, paper has found unique applications. In order to determine the applicability of a desired product, the interaction of the paper surface with different chemicals needs to be understood. In this work, adsorption/desorption experiments of volatile organic compounds from paper samples were studied. Several factors that could influence the adsorption/desorption behavior were investigated. The method is based on headspace solid-phase microextraction and gas chromatography flame ionization detection (HS-SPME-GC/FID) or mass spectrometry (HSSPME-GC/MS). It was shown that the polar model compounds are much stronger adsorbed on the paper than the nonpolar ones. An influence of the chemical nature of the paper samples was observed, the more hydrophilic the paper, the more polar compounds adsorb. By increasing the humidity, the sorption rates significantly decreased.
\end{abstract}

Keywords: paper, porosity, food packaging, aroma, ink, sorption, organic compounds, SPME, GC analysis

\section{INTRODUCTION}

Paper is the material of choice for a broad range of applications that are commonly used in our everyday life. It has found unique applications in information storage, medicine and packaging to transport and protect goods (examples include bags for granular materials or food). The interest in applying paper in many different fields is still increasing, because it has a variety of favorable characteristics. These characteristics include its sustainability and biodegradability, combined with excellent mechanical properties. Furthermore, it is a cost-effective material, with superior printability.

As paper finds applications in a large range of fields, its properties have to be adjusted and optimized to tailor the products. The properties depend on the fiber and pore networks and the additives that can be included in the structure. The porosity of paper is one of its major inherent characteristics, which significantly influences its applicability. To optimize the material features, fundamental knowledge about the pore network of paper and its transport relevance is needed. The pore structure determined at one location is not necessarily the same at another location, as paper sheets are non-uniform and the fiber dimensional properties are subject to natural variation. ${ }^{1}$ Furthermore, the pore sizes can be broadly distributed, ranging between a few nanometers and $50 \mu \mathrm{m}$, depending on the pore types. There are two different pore types inherently found in paper sheets, the inter-fiber pores and the intrafiber pores. The inter-fiber pores are formed between crossing cellulose fibers; the intra-fiber pores are in the nanometer range and are found on the fiber wall. ${ }^{1-4}$ Due to this very distinct nature of the pores, it is crucial to gain a deeper understanding of the pore sizes and the resulting active surface area, which can get quite large due to the nanometer pores on the fiber walls.

So far, the porous structure of paper can be characterized by mercury intrusion ${ }^{5}$ and recent developments have been made in characterizing the $3 \mathrm{D}$ pore structure of paper with X-ray microcomputer tomography $(\mu-\mathrm{CT}){ }^{6}$ This technique offers a resolution from the micrometer down to

Cellulose Chem. Technol., 54 (5-6), 515-522(2020) 
the sub-nanometer range, ${ }^{6}$ and the contrast between fiber and void is constant throughout the volume. ${ }^{2}$ This 3D knowledge is required for prediction of transport processes through paper, therefore the transport relevant pores have to be identified to further develop the mechanical properties of paper. Furthermore, the available surface area resulting from the porosity has to be identified in order to understand the interaction of paper with fluids and chemicals. This understanding is particularly important when paper is used in packaging applications. In the sector of food packaging, paper and board are currently the most commonly used packaging materials. ${ }^{7}$ Although paper is already the prime choice for fast and durable packaging of dry food, its application is also challenging because articles and materials that are considered to come into contact with food should not change the food in any unacceptable way. The materials must be sufficiently inert to preclude the transfer of substances from the packaging into the food and they should protect the organoleptic properties of the food. ${ }^{8}$

Although the 3D pore structure of paper can be characterized with techniques such as $\mu$-CT, $2,5,6$ there is no information obtained on how different paper types with varying pore structures interact with chemicals that can be found, for example, as aroma compounds in food. Furthermore, in most cases where paper is used as a packaging material, it needs to be labelled to either store information or to design the packaging. Therefore, it is of utmost importance to understand not only the interaction of the packaging material with the food, but also the interaction of the packaging material with other chemical products, such as printing inks, to be able to carefully and properly select the type of paper used for food packaging and the composition of printing inks.

One requirement for printing is the wettability of the paper surface with the ink. Therefore, the interactions of paper with chemicals of different nature need to be investigated. These interactions depend on the compounds, as well as on the pore structure and its resulting surface area, as the surface area determines the adsorption properties of a paper. To optimally select the paper type and the composition of the printing ink, the drying process of the ink on the paper surface needs to be understood.

Herein, we successfully demonstrate that the adsorption and desorption properties of different compounds on paper can be measured using headspace solid-phase microextraction and gas chromatography, flame ionization detection or mass spectrometry (HS-SPME-GC/FID or HSSPME-GC/MS). We selected a group of organic compounds, polar and non-polar, and determined their sorption rates on different paper types. In the first phase, the sorption behavior of the compounds on a sized paper sample was investigated to determine the available surface areas on the paper sheet. Therefore, different paper sample sizes were investigated. Furthermore, a solution of organic compounds was prepared in different solvents to evaluate their influence on the adsorption and desorption behavior of the compounds. As the results indicated that the solvent influences the sorption rates of the compounds, further measurements were carried out with sized and unsized paper samples in order to investigate whether the sizing added to the paper and therefore the more hydrophobic nature of the paper has an influence on the sorption process. To monitor the influence of water, as it is always present and some inks are water-based, and furthermore, it is the most polar solvent, its influence on the sorption rates was studied. The obtained results were discussed in terms of interactions between solvents, chemicals and paper surfaces, as well as the adsorption/desorption behavior of the selected compounds.

\section{EXPERIMENTAL \\ Paper samples}

For the sorption studies, three virgin fiber paper samples of different qualities were used. In order to investigate the available surface area that is determined by the porosity of a paper sheet, the studies were carried out using unbleached Kraft pulp based paper grades. To determine whether the sizing added to the paper governs the sorption process and to monitor the influences of solvents and water, two different office paper grade samples were used, one of them sized and the other one unsized. Their characteristics are listed in Table 1.

\section{Reagents and solutions}

The study was carried out with a group of volatile model compounds with different polarity, structure, boiling point and molecular weight. The polar compounds were chosen to represent molecules that might be found as aroma compounds in food. The selected chemicals are the following: (1) n-decane (124-18-5), b.p. $174{ }^{\circ} \mathrm{C}$; (2) p-cymene (99-87-6), b.p. $177{ }^{\circ} \mathrm{C}$; (3) 2-ethylphenol (90-00-6), b.p. $195-197{ }^{\circ} \mathrm{C}$; (4) menthol (89-78-1), b.p. $212{ }^{\circ} \mathrm{C}$; (5) 4-ethylguaiacol (2785-89-9), b.p. $234-236^{\circ} \mathrm{C}$; (6) n-tridecane (629-50- 
5), b.p. $234{ }^{\circ} \mathrm{C}$; (7) methyleugenol (93-15-2), b.p. 255 ${ }^{\circ} \mathrm{C}$; (8) methyl undecanoate (1731-86-8), b.p. 247-249 ${ }^{\circ} \mathrm{C}$ and (9) n-hexadecane (544-76-3), b.p. $287{ }^{\circ} \mathrm{C}$. All chemicals were of analytical grade. P-cymene, 2ethylphenol, menthol, 4-ethylguaiacol and methyleugenol were purchased from Sigma Aldrich (Germany), n-tridecane, methyl undecanoate and nhexadecane were purchased from Fluka (Switzerland), n-decane was purchased from Merck (Germany). A standard solution containing all the compounds in a mixture was prepared in ethylacetate $\left(\right.$ Picograde $\left.^{\circledR}\right)$, purchased from Promochem (Germany), with a concentration of $1 \mathrm{~g} / \mathrm{L}$. The standard solution was further diluted to concentrations ranging from 10 to 50 $\mathrm{mg} / \mathrm{L}$ in methanol (LC-MS HiPerSolv), purchased from VWR (Germany), and to a concentration of 10 $\mathrm{mg} / \mathrm{L}$ in hexane $\left(\right.$ Picograde $\left.^{\circledR}\right)$, purchased from Promochem (Germany). In order to investigate the influence of water on the desorption rates, tap water was used.

Table 1

Characteristics of the paper samples used in the present study

\begin{tabular}{lcc}
\hline Sample & Type & Sizing \\
\hline S1 & Unbleached Kraft pulp based paper & Sized \\
S2 & Office paper & Sized \\
S3 & Office paper & Unsized \\
\hline
\end{tabular}

\section{Analytical procedures \\ Determination of the available surface areas on paper}

All adsorption/desorption experiments were performed under equilibrium conditions. Paper strips of $\mathrm{S} 1$ with dimensions of $1.5 \times 1.5 \mathrm{~cm}$ and an average weight of approximately $20 \mathrm{mg}, 1 \mathrm{x} 1 \mathrm{~cm}$ and an average weight of approximately $10 \mathrm{mg}, 1 \times 0.5 \mathrm{~cm}$ and an average weight of approximately $5 \mathrm{mg}, 0.5 \mathrm{x}$ $0.5 \mathrm{~cm}$ and an average weight of approximately $3 \mathrm{mg}$, and $0.5 \mathrm{x} 0.2 \mathrm{~cm}$ and an average weight of approximately $1 \mathrm{mg}$ were placed in $20 \mathrm{~mL}$ headspace crimp vials. The paper samples were spiked with the mixture of the nine standard compounds diluted in methanol, with concentrations ranging from 10 to 50 $\mathrm{mg} / \mathrm{L}$. In absolute amounts, 100-500 ng per compound were spiked onto the paper samples. Furthermore, a solution of the standard compounds of $10 \mathrm{mg} / \mathrm{L}$ was prepared in hexane and spiked onto the paper samples in order to monitor the influence of a different solvent.

The samples were analyzed using HS-SPMEGC/FID. The rates of the sorbed compounds on the paper samples were calculated by using the ratios of the areas obtained for the compounds on the paper with respect to pure standard areas, which refer to $100 \%$ desorption. Pure standard areas were obtained by measuring the same amount of standard under the same conditions, but without placing the paper sample into the headspace vial. Determinations were carried out in triplicate. In order to ensure that the used compounds are not inherently present in the paper, blank paper samples were measured under the same conditions.

\section{HS-SPME-GC/FID analysis}

The samples were extracted using HS-SPME with a 2 cm stable flex 50/30 $\mu \mathrm{m}$ DVB/Carboxen/PDMS fiber. Figure 1 visualizes a HS-SPME-GC experiment. First, the sample is placed in a headspace vial (A), the vial is closed and then thermostated at a constant temperature until equilibrium of the analytes is reached between the sample and the gas phase above the sample. After that, the SPME fiber (B) is automatically transferred into the vial and an equilibrium of the analytes is reached between the sample, the headspace and the fiber. The analytes are allowed to adsorb onto the fiber for a certain time (C). The fiber is then transported to the GC injector, where the analytes are desorbed from the fiber into the GC column and analyzed in the usual way. The incubation temperature was set to $70{ }^{\circ} \mathrm{C}$, the extraction time was $15 \mathrm{~min}$ and the desorption time was set to 6 min. The GC unit was an Agilent 6890 series gas chromatograph, equipped with a PAL CTC Analytics autosampler and a flame ionization detector. The compounds were separated on a Zebron ZB-5MS column $(30 \times 0.25 \mathrm{~mm} ; 0.25 \mu \mathrm{m})$, purchased from Phenomenex (USA). The following GC parameters were kept constant: detector temperature, $320{ }^{\circ} \mathrm{C}$; injector temperature, $270{ }^{\circ} \mathrm{C}$; injection mode: splitless. The column temperature program was: $50{ }^{\circ} \mathrm{C}(1 \mathrm{~min})$, from $50{ }^{\circ} \mathrm{C}$ at a rate of $8{ }^{\circ} \mathrm{C} / \mathrm{min}$ to $270{ }^{\circ} \mathrm{C}(1 \mathrm{~min})$. Carrier gas was helium, with a constant flow rate of $1.6 \mathrm{~mL} / \mathrm{min}$.

\section{Monitoring the influence of different conditions - solvent, sizing, water - on the sorption process}

Paper strips of S2 and S3, with dimensions of $1.5 \mathrm{x}$ $1.5 \mathrm{~cm}$ with an average weight of approximately 20 $\mathrm{mg}$, were placed in $20 \mathrm{~mL}$ headspace crimp vials. The paper samples were spiked with the mixture of nine standard compounds diluted in methanol or hexane with a concentration of $10 \mathrm{mg} / \mathrm{L}$. In order to allow the compounds to adsorb via the gas phase onto the paper, the solution was carefully introduced on the walls of the vial and the compounds were allowed to equilibrate for $24 \mathrm{~h}$, at room temperature. 
To investigate the effect of humidity on the sorption rates, $20 \mu \mathrm{L}$ of water was deliberately added to the samples before the standard compounds were added.
The samples were analyzed using HS-SPMEGC/MS. The sorption rates were calculated as described above.

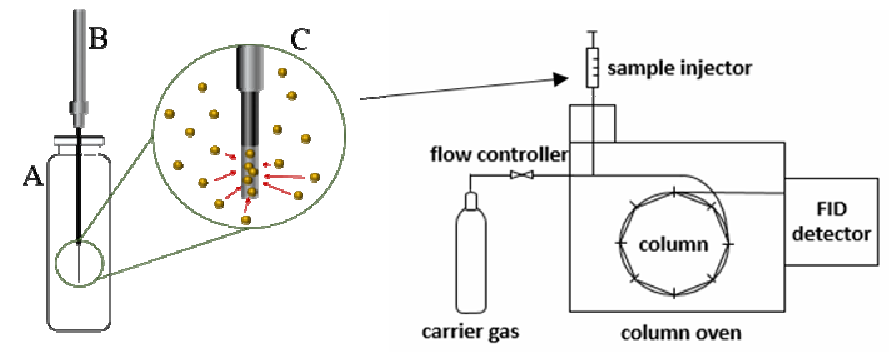

Figure 1: Principles of headspace - solid-phase microextraction - gas chromatography

\section{HS-SPME-GC/MS analysis}

The samples were extracted using HS-SPME with a $2 \mathrm{~cm}$ stable flex 50/30 $\mu \mathrm{m}$ DVB/Carboxen/PDMS fiber. The incubation temperature was set to $70{ }^{\circ} \mathrm{C}$, the extraction time was $15 \mathrm{~min}$ and the desorption time was set to $6 \mathrm{~min}$. The GC unit was an Agilent $7890 \mathrm{~A}$ series gas chromatograph, equipped with a PAL CTC Analytics autosampler and a mass spectrometer, 5975 C VLMSD with Triple Axis Detection. The compounds were separated on an Rxi-5ms column (30 x $0.25 \mathrm{~mm} ; 0.25 \mu \mathrm{m}$ ), purchased from Restek (USA). The following GC parameters were kept constant: detector temperature, $230{ }^{\circ} \mathrm{C}$; injector temperature, 270 ${ }^{\circ} \mathrm{C}$; injection mode: splitless. The column temperature program was: $50{ }^{\circ} \mathrm{C}(1 \mathrm{~min})$, from $50{ }^{\circ} \mathrm{C}$ at a rate of 8 ${ }^{\circ} \mathrm{C} / \mathrm{min}$ to $270{ }^{\circ} \mathrm{C}$ (1 min). Carrier gas was helium with a constant flow rate of $2.4 \mathrm{~mL} / \mathrm{min}$. Data were collected for a scan range comprising 20-350 amu.

\section{RESULTS AND DISCUSSION Determination of available surface areas on paper}

Since paper is a porous material, the resulting surface areas determine its adsorption strength. The adsorption strength, in turn, determines the interaction of paper with volatile compounds, as they can be found as aroma compounds in food or as components of printing inks. To understand the interaction of paper with fluids and chemicals, the adsorption/desorption behavior of the selected compounds was investigated. For this purpose, the sorption rates of the compounds on the paper samples were calculated.

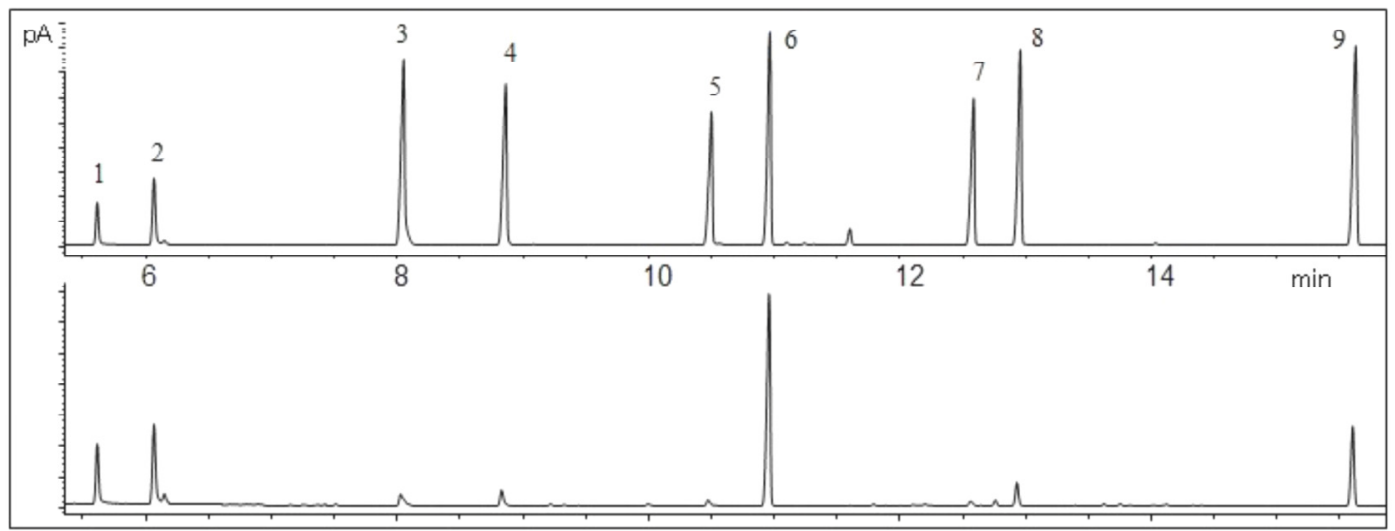

Figure 2: GC-FID chromatogram of the pure model compounds diluted in methanol (above) and the paper samples spiked with the compounds (below). The elution order is the following: (1) n-decane, (2) p-cymene, (3) 2-ethylphenol, (4) menthol, (5) 4-ethylguaiacol, (6) n-tridecane, (7) methyleugenol, (8) methyl undecanoate, (9) n-hexadecane

The sorption rates of compounds bound to the paper are given in percentage and were calculated by using the ratio of the area obtained for the compound spiked on the paper with respect to the pure standard area; the area of the compound in the pure standard refers to $100 \%$ desorption. Figure 2 gives an example of a GC-FID 
chromatogram of the pure standard and the paper sample spiked with the standard.

Sorption rates were calculated for different paper sizes $(20,10,5,3$ and $1 \mathrm{mg})$ and standard

A

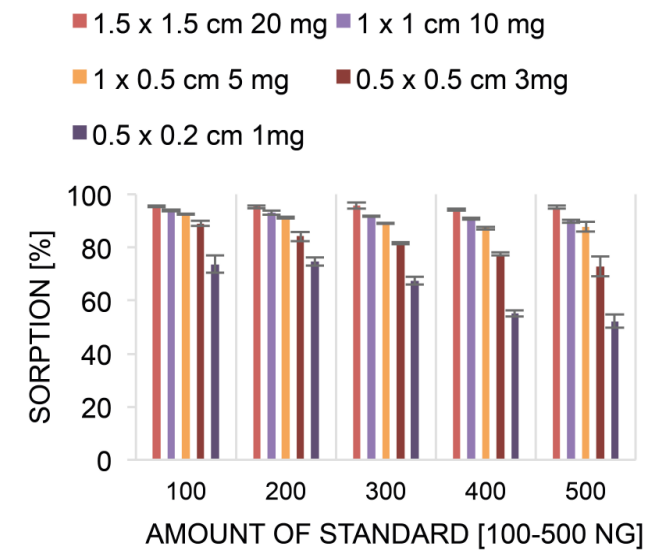

C 4-ETHYLGUAiAcol

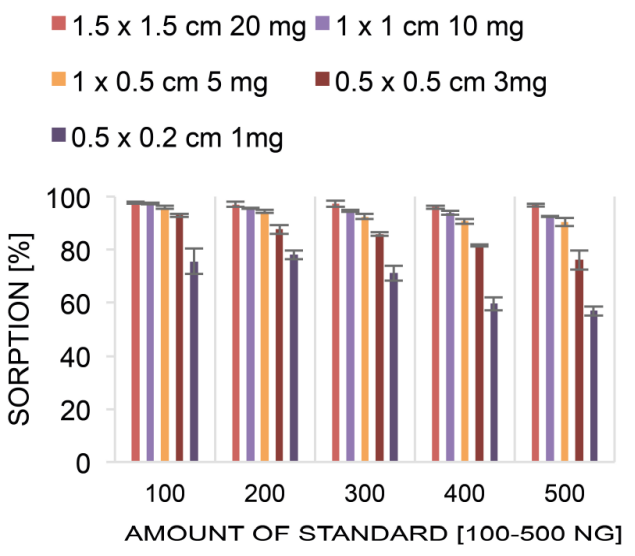

amounts (100-500 $\mathrm{ng})$ in order to investigate the saturation effect of the paper surface areas.

B MENTHOL
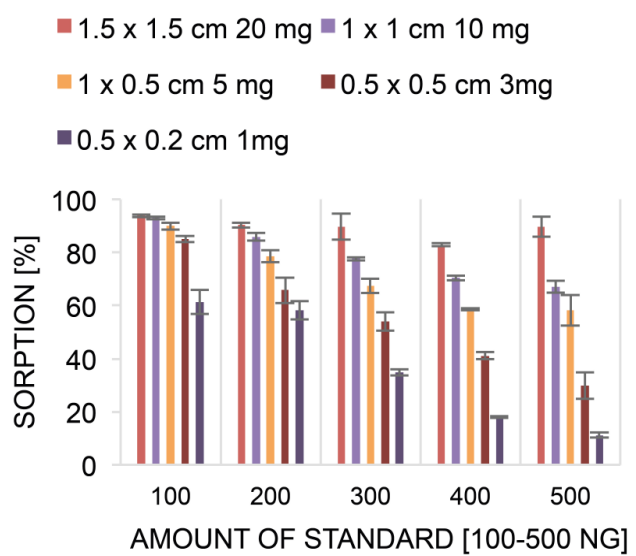

D METHYLEUGENOL

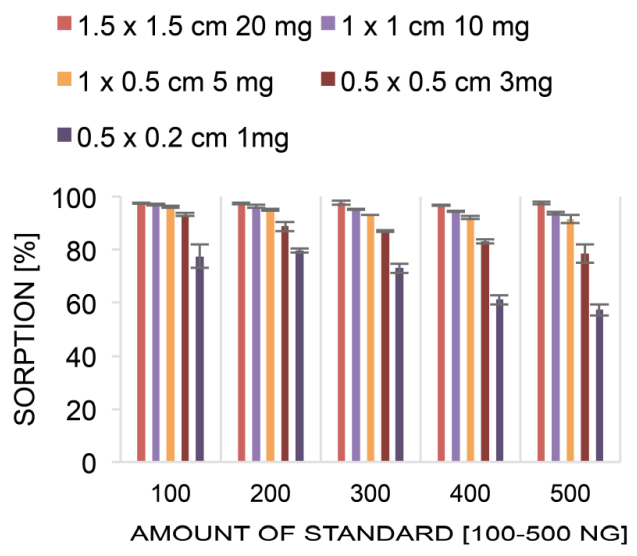

Figure 3 (A-D): Sorption rates of the four most polar aroma compounds on paper sample S1 with different paper sizes and increasing amounts of standard compounds

Figure 3 (A-D) shows the sorption rates of the four most polar model compounds, dissolved in methanol, on the paper samples. The obtained results show the ability of molecules of various polarities and volatilities to adsorb and desorb from the paper surface and thus simulate the interaction of volatile compounds with paper. The higher the sorption rates, the more compounds are adsorbed on the paper surface, indicating more available surface areas on the paper sheets. Differences in the sorption behaviors of the molecules can be recognized. Whereas the polar molecules remain on the paper surface, the nonpolar molecules desorb much more easily and are almost completely released (results are not shown). For the most polar molecules, such as 2ethylphenol, 4-ethylguaiacol and methyleugenol, very high sorption rates were obtained, indicating a strong interaction with the paper sheet.

Triantafyllou et al., who calculated the adsorption isotherms of selected surrogates between paperboard samples and air, found in their study that acetophenone (the compound with the highest volatility in their group) adsorbed to a 
higher rate on the board matrix than naphthalene with a higher boiling point. They explained their results by the fact that acetophenone has a higher affinity to the paper fibers. ${ }^{10}$ Also, the data of Biedermann-Brem et al. confirm a strong absorption of polar substances into the paperboard. Furthermore, they showed that a saturation of adsorbing and absorbing sites on a paperboard occurs more rapidly for alkanes than for more polar substances. ${ }^{11}$ The same effect was observed by Walzl et al. in their permeation studies of aroma compounds through paper. They observed that the aroma compounds, except for menthol, did not permeate through the paper. These results indicate again a strong interaction of aroma compounds with the polar groups of the paper surface. ${ }^{12}$ Similar results were found by Poças et al., as they stated that the concentration of a migrant that is released from a paper sample is greatly determined by its polarity and that the chemical character of the cellulosic fiber plays an important role for the interaction with different substances. The cellulosic fibers are hydrophilic and largely non-ionic, whereas the lignin fraction has aromatic phenolic units with hydrophilic and hydrophobic domains that are anionic and therefore influencing the molecules behavior on the fiber. ${ }^{13}$ In our study, even when the amount of paper and therefore the available surface area was decreased to $1 \mathrm{mg}$ and the amount of standard was increased to $500 \mathrm{ng}$ of each compound, around $50 \%$ of the initial amount of compound remained on the paper surface. This can be explained by the fact that there might be sufficient surface area available for the considered amount of compounds or that the compounds might form molecular layers on the fiber surface. However, our results confirm that polar compounds have a very high affinity to the cellulosic fibers of the paper sheets.

\section{Influence of solvent characteristics}

One thing that has to be taken into account is that the molecules used were dissolved in the relatively polar solvent methanol, which could also interact with the paper surface in the same way the model compounds do. In order to investigate the influence of the solvent, methanol was changed to the non-polar solvent hexane. Therefore, a solution of the compounds with an amount of $100 \mathrm{ng}$ each $(10 \mathrm{mg} / \mathrm{L})$ was prepared in hexane and spiked onto $20 \mathrm{mg}$ paper samples. The only compound that remained adsorbed on the paper surface was 2-ethylphenol, with a sorption rate of about $80 \%$, all other compounds were released. This indicates that a non-polar solvent also interacts with the paper surface and is able to disrupt the strong interaction between the fiber and the other compounds present in the standard. This could be explained by the fact that, for hexane, a covering effect is observed. The hexane molecule $\left(\mathrm{C}_{6} \mathrm{H}_{14}\right)$ is bigger in size than the methanol molecule $\left(\mathrm{CH}_{4} \mathrm{O}\right)$, therefore it needs more space on the paper when interacting with the fibers and blocks free pore space for other compounds. 2-Ethylphenol is the smallest polar molecule in the group and can therefore still adsorb onto the paper surface. Comparable results were obtained by Henögl et al., who did desorption experiments with the polar molecule deuterated methanol and the non-polar molecule decane on cellulose films. The results indicated that the molecules strongly influence the surface structure of cellulose. ${ }^{14}$

\section{Monitoring the influence of different conditions - solvent, sizing, water - on the sorption process}

In order to avoid intrusion of the molecules into the fiber upon direct spiking onto the paper samples, the molecules were allowed to adsorb via the gas phase in the following experiments. It was shown in previous experiments that the paper incorporates the compounds from the gas phase also eagerly, and there was no difference in the sorption rates between spiking directly on the paper and applying the solution on the wall of the HS-vial.

\section{Influence of paper type}

In the above mentioned results, it was shown that the sorption rates are influenced by the chemical nature of the compounds and the nature of the solvent used to dilute the compounds, but there might be several more factors that could influence the adsorption/desorption behavior. These factors might include the type of paper and the presence of water. In order to investigate the influence of the paper type, two office paper samples, one of them sized, S2, and the other one unsized, S3, were used. The sizing added to the paper influences its chemical character by increasing its hydrophobicity, and in turn, improving its writing property and printability. Figures $4 \mathrm{~A}$ and $\mathrm{B}$ show the sorption rates of the compounds, diluted in methanol or hexane, respectively, from the two paper samples S2 and S3. From Figure 4, two things are noticeable. 
First, the covering effect of the hexane molecules, which was also observed in the previous measurements of sample S1, is evident as the sorption rates of the compounds, when hexane is used as solvent (Fig. 4B), are much lower than with methanol as solvent (Fig. 4A). The only compound that remains on the sized paper with hexane is again 2-ethylphenol, all other compounds are released. The second fact is that the chemical character and hence the sizing added to the paper has an influence on the sorption process. Figure 4 shows significant differences in the sorption behavior of the compounds from the sized and the unsized paper sample. From Figure $4 \mathrm{~A}$, where methanol was used as solvent, it is obvious that the polar as well as the non-polar compounds are more strongly adsorbed on the unsized paper sample (S3), a fact that can be explained by its more hydrophilic nature. The fact that the paper's nature governs the adsorption/desorption process can also be observed with hexane as solvent, shown in Figure 4B. While on the sized sample 2-ethylphenol is the only compound that stays, on the unsized sample, 2-ethylphenol and 4-ethylguaiacol are strongly adsorbed.
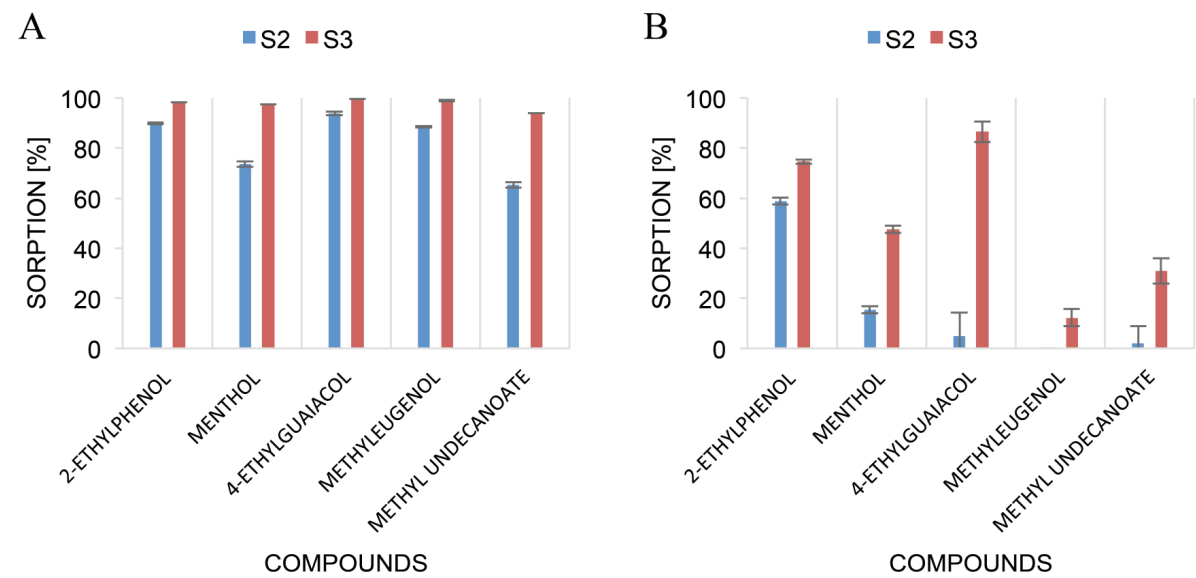

Figure 4: Sorption rates of the five polar model compounds on sized (S2) and unsized (S3) paper samples (the compounds were diluted in methanol (A) and hexane (B))

s2 $m$ S3

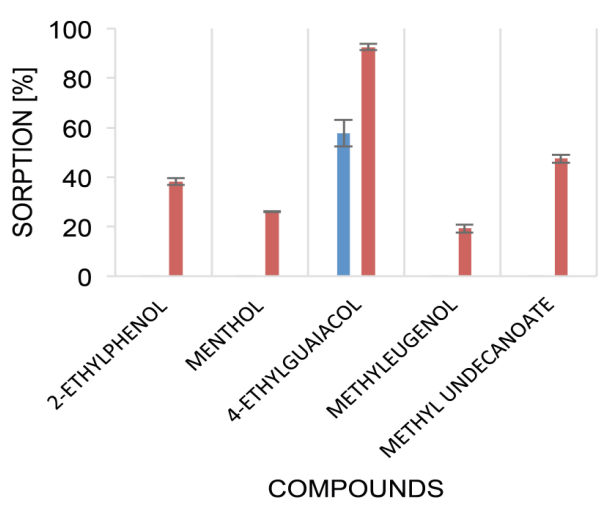

Figure 5: Sorption rates of the five polar model compounds on sized (S2) and unsized (S3) paper samples with deliberately added water (the compounds were diluted in methanol)

\section{Influence of water}

The second factor that might influence the desorption process is the presence of water. The investigation of the influence of humidity is important because there is always water present in the air and there are several printing inks based on water; furthermore, it is the most polar solvent. In paper, water could deactivate absorptive sites and increase the vapor pressure of absorbed substances. ${ }^{11}$ In order to investigate the effect of humidity, water was deliberately added to the paper samples before spiking with the model compounds, which were diluted in methanol. The results for the two paper samples are shown in 
Figure 5. As expected, the water molecules block active sites on the paper surface and therefore displace the other molecules. This displacement effect is observed for both paper types, however on the unsized paper (S3) the sorption rates are higher than on the sized one, but still much lower than without additional water (Fig. 4A). These results are in agreement with those obtained by Biedermann-Brem et al., who observed slightly higher migration of their substances from a humidified paperboard sample. ${ }^{11}$

\section{CONCLUSION}

Paper is a material that is used in a broad range of applications. Especially for the packaging of dry food it is the prime choice and in most cases it needs to be labeled or printed. Therefore, it is of utmost importance to understand the interactions between paper and the chemicals that might be present as aroma compounds in food, but also as volatile compounds in inks, and to monitor the influence of factors like paper types, nature of chemicals and solvents. Here, we demonstrate that, with a simple SPME procedure followed by GC-FID or GC-MS analysis, the adsorption/desorption behavior of selected model compounds can be determined from different paper samples, serving as an estimation whether the compounds might stick on the paper surface and in the case of printing, contribute to successful printing. The calculated sorption rates highly depend on the chemical nature of the compounds as the polar compounds are much stronger adsorbed than the non-polar ones. There is sufficient surface area available for the compounds to strongly adsorb, even on very small paper samples. Furthermore, it was seen that the sorption rates are influenced by the paper type. The more hydrophilic the paper, the higher is the rate of bound compounds. However, this fact also applies to the various solvents tested, as onto more hydrophilic paper samples more solvent molecules are attached. For different solvent types, different effects were observed. With methanol, the model compounds stayed to a very high extent on both paper types (sized and unsized); with hexane, a covering effect was observed as the large hexane molecules block the available spaces on the paper surface and therefore the other compounds were released. When water was added to investigate the effect of humidity on sorption rates, a displacement effect was observed as the water molecules seem to be more strongly bound to the paper surface than the other model compounds. As a final conclusion, it is important to carefully select the paper type, the type of food and the composition of the printing inks, as all these factors might determine the applicability of a desired product.

ACKNOWLEDGMENT: Financial support from the Federal Ministry for Digital and Economic Affairs and from the National Foundation for Research, Technology and Development, Austria, via the Christian Doppler Laboratory for Mass Transport through Paper is gratefully acknowledged.

\section{REFERENCES}

1 S. Borodulina, E. L. G. Wernersson, A. Kulachenko and C. L. Luengo Hendriks, Phys. Nord. Pulp Pap. Res. J., 31, 469 (2016), https://doi.org/10.3183/npprj2016-31-03-p469-478

2 M. Axelsson and S. Svensson, Pattern. Anal. Appl., 13, 159 (2010), https://doi.org/10.1007/s10044-009$0146-1$

3 X. Zhao, S. Wang, X. Yin, J. Yu and B. Ding, Sci. Rep., 6, 1 (2016), https://doi.org/10.1038/srep35472

4 P. Lu and Y. Hsieh, Carbohyd. Polym., 87, 564 (2012), https://doi.org/10.1016/j.carbpol.2011.08.022

5 M. J. Moura, P. J. Ferreira and M. M. Figueiredo, Powder Technol., 160, 61 (2005), https://doi.org/10.1016/j.powtec.2005.08.033

6 S. Rolland Du Roscoat, J. F. Bloch and X. Thibault, J. Phys. D, Appl. Phys., 38, 78 (2005), https://doi.org/10.1088/0022-3727/38/10A/015

7 G. Chinga-Carrasco, J. Microsc., 234, 211 (2009), https://doi.org/10.1111/j.1365-2818.2009.03164.x

8 J. Muncke, Food Packaging Forum, (2012), accessed January 20, 2020 https://www.foodpackagingforum.org/food-packaginghealth/food-packaging-materials

9 The European Parliament and the Council of the European Union, Official Journal of the European Union, L 338/4 4, (2004), https://eurlex.europa.eu/LexUriServ/LexUriServ.do?uri=OJ:L:20 04:338:0004:0017:en:PDF

10 V. I. Triantafyllou, K. Akrida-Demertzi and P. G. Demertzis, J. Chromatogr. A, 1077, 74 (2005), https://doi.org/10.1016/j.chroma.2005.04.061

11 S. Biedermann-Brem, M. Biedermann and K. Grob, Packag. Technol. Sci., 30, $91 \quad$ (2017), https://doi.org/10.1002/pts.2278

12 A. Walzl, S. Kopacic, W. Bauer and E. Leitner, Food Addit. Contam. A, 36, 976 (2019), https://doi.org/10.1080/19440049.2019.1600747

13 M. de F. Poças, J. C. Oliveira, J. R. Pereira, R. Brandsch and T. Hogg, Food Control., 22, 303 (2011), https://doi.org/10.1016/j.foodcont.2010.07.028

14 E. Henögl, V. Haberl, J. Ablasser and R. Schennach, Front. Mater., 6, 1 (2019), https://doi.org/10.3389/fmats.2019.00178 